\title{
Seismic reflection survey of the crustal structure beneath Unzen volcano, Kyushu, Japan
}

\author{
Satoshi Matsumoto $^{1}$, Hiroshi Shimizu ${ }^{1}$, Masazumi Onishi ${ }^{2}$, and Kenji Uehira ${ }^{1}$ \\ ${ }^{1}$ Institute of Seismology and Volcanology, Kyushu University, Shimabara 855-0843, Japan \\ ${ }^{2}$ JAPEX, SAPIA Tower, 1-7-12, Marunouchi, Chiyoda-ku, Tokyo 100-0005, Japan
}

(Received July 8, 2010; Revised November 16, 2011; Accepted November 21, 2011; Online published June 28, 2012)

\begin{abstract}
Unzen volcano is located in the western part of Kyushu, Japan. We carried out a seismic re ection survey at Unzen volcano in order to elucidate the structure of the volcano. Although the survey was conducted in a volcanic area under dif cult conditions, such as arti cial noises and a complex structure, we were able to resolve the structure beneath the pro le using vibrator sources and a large number of stacking signals. The processed depth sections con rmed that Unzen volcano developed in a graben structure, as has been suggested in other geological studies. We imaged many subsurface normal faults shallower than $1 \mathrm{~km}$. These faults, mostly covered with volcanic lava and deposits, were identi ed at the surface. Strong re ectors were found at a depth of approximately $3 \mathrm{~km}$. They were located just above the pressure source of the latest eruption, as inferred from geodetic data. The geometric relationship between the re ection image, the pressure source location, and the lava dome suggests that the conduit from the lava dome could connect to the magma chamber located $4 \mathrm{~km}$ away from the lava dome.
\end{abstract}

Key words: Unzen volcano, seismic re ection, graben, magma.

\section{Introduction}

Unzen volcano is located at the center of the Unzen graben (Fig. 1) in the Shimabara Peninsula, west Kyushu, Japan. The most recent activity started in 1990 and went on until 1995. In 1990, Unzen volcano started erupting, producing a new lava dome at the summit. The total volume of magma from the latest eruption was $2.1 \times 10^{8} \mathrm{~m}^{3}$ (Nakada et al., 1999). Prior to the eruption, seismicity was high toward the western part of the graben and low on the eastern segment, as shown in Fig. 2 (Umakoshi et al., 2001).

The Unzen graben is characterized by normal faults with east-west strikes. An N-S tensile stress is dominant in the graben (Hoshizumi et al., 2003). The geological structure of Unzen volcano, reported by Hoshizumi et al. (2003), is shown in Fig. 3. Unzen volcano started to develop in $0.5 \mathrm{Ma}$, and its growth history can be divided into two stages (Hoshizumi et al., 2005). During the younger stage $(<120 \mathrm{ka})$, the lava and ash ows generated due to volcanic eruptions were deposited toward the eastern half of the volcano. Several cones (lava domes) can be found in the central part of the graben (indicated by yellow triangles in Fig. 3). The youngest cone, called Fugendake, is located at the center of the graben. The most recent eruption (denoted by red triangles in Fig. 3) started on November 17 , 1990, slightly east of Fugendake. According to the results of a drilling project - the Unzen Scienti c Drilling Project (USDP)—-many dykes and veins of different compositions

Copyright (C) The Society of Geomagnetism and Earth, Planetary and Space Sciences (SGEPSS); The Seismological Society of Japan; The Volcanological Society of Japan; The Geodetic Society of Japan; The Japanese Society for Planetary Sciences; TERRAPUB.

doi:10.5047/eps.2011.11.006 had intruded into the conduit zone beneath the lava dome (Nakada et al., 2005).

Kohno et al. (2008) proposed a model of the pressure sources in the case of the latest eruption and the posteruption deformation, using geodetic data such as leveling survey data. They observed four pressure sources beneath Unzen volcano and showed that magma ascended from beneath Chijiwa Bay (west of Shimabara Peninsula) to the crater created by the eruption. The depths of the sources increased towards the west from the lava dome. Umakoshi et al. (2001) determined the cut-off depth of the earthquake distribution from an E-W cross-section and observed that the average depth of the distribution decreased eastwards towards the lava dome. They also determined the variations in the focal mechanism with depth; these variations suggest the presence of high-temperature, ductile, and low- $Q$, bodies below the cut-off depth. They reported that the seismic activity started beneath Chijiwa Bay, migrated eastwards, and became extremely high just below the lava dome before the eruption. This phenomenon suggests that magma ascended to the lava dome from Chijiwa Bay. The relationship between the seismic activity and the magma sources is shown in Fig. 2.

These above-mentioned studies succeeded in outlining the 1990-1995 eruption and the structure of Unzen volcano. However, the mechanism of the latest eruption and the formation of the Unzen graben are not yet clearly understood. For instance, Kohno et al. (2008) suggested that one of the pressure sources that supplied magma exists in a very shallow region beneath the volcano. This might have had a strong effect on the medium around the pressure source. The effect could be detected as a heterogeneity in 


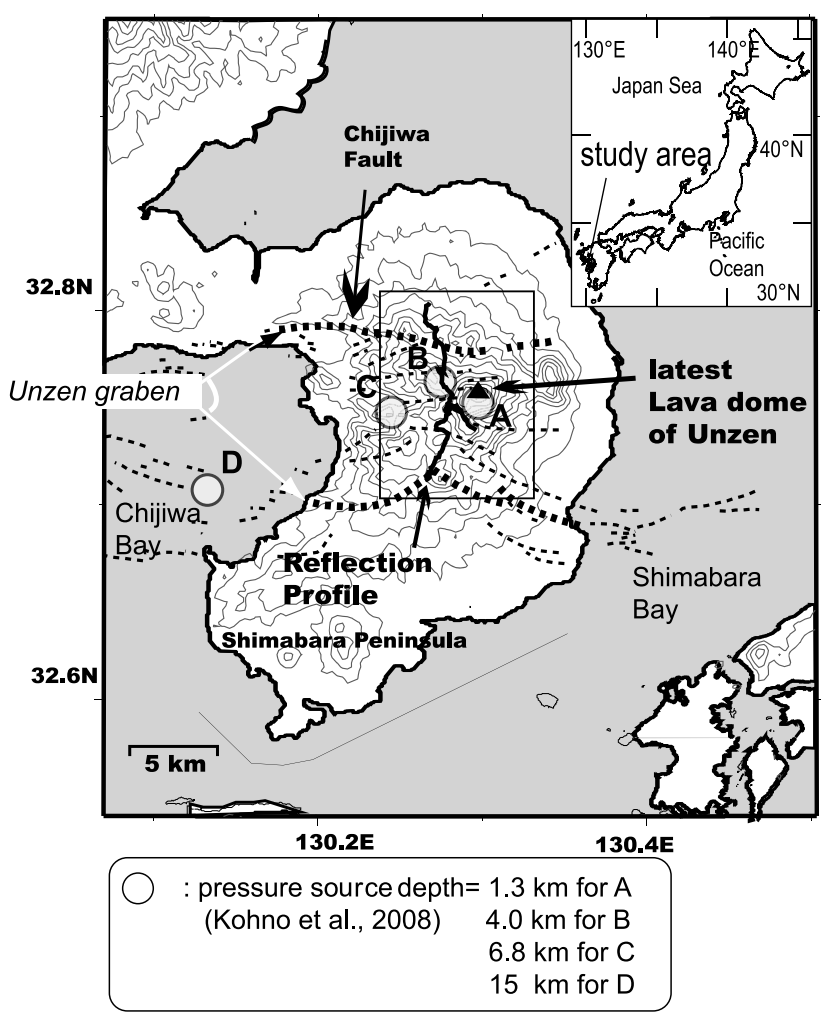

Fig. 1. Map view of the profile in the seismic reflection survey. The solid line in the middle of the figure represents the survey line. The active faults (The Research Group for Active Faults of Japan, 1991) are denoted by dashed lines. The Unzen graben is the area sandwiched between two active faults (thick dashed lines). The solid triangle represents the lava dome formed during the last eruption. The light grey lines are the contours of the topography with $0.1-\mathrm{km}$-height intervals. The open circles denote the locations of the pressure sources, as estimated by Kohno et al. (2008). Their depths are listed at the bottom of the figure. The solid rectangle shows the area whose geological map is shown in Fig. 3.

the medium, which can prove the existence of the magma body. In addition, subsurface deformation of the layered structure can provide us with valuable information on the growth of the graben and the intrusion of magma. Seismic reflection data can be used to detect the fine velocity contrast beneath the volcano, since the reflection phases are more sensitive to small-scale heterogeneities than are the refracted and/or direct waves. In this study, we have conducted a seismic reflection survey to help understand the subsurface structures of Unzen volcano.

The structures of volcanic regions in oceans have been described in detail by means of reflection surveys (Suzuki et al., 1992). For example, Collier and Sinha (1990), and Singh et al. (2006), detected magma chambers at mid-ocean ridges using reflection surveys. They obtained fine reflection images of the magma chambers, faults, and the structure of the graben formed by crustal accretion at the ridge. In contrast, reflection surveys have rarely been conducted in volcanic regions on land because of the many difficulties posed by factors such as artificial noise and complex geological structures (e.g. lava and volcanic deposits). Despite these difficulties, a seismic reflection survey has been conducted in this study to obtain detailed images of the structures beneath Unzen volcano.

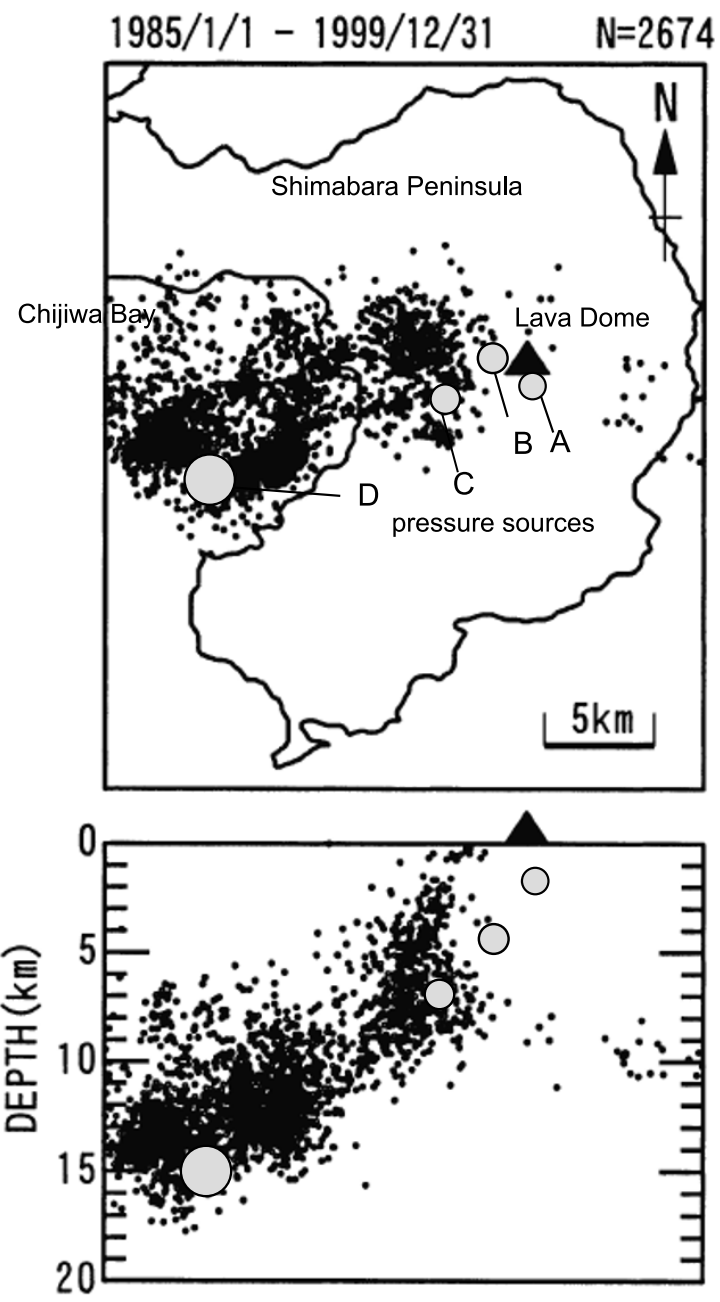

Fig. 2. Plane view and vertical cross-section in the east-west direction of hypocenter distribution and pressure sources (Kohno et al., 2008). The dots denote the hypocenters obtained for the period 1985-1999 by Umakoshi et al. (2001). The grey circles are the pressure sources (Umakoshi et al., 2001).

\section{Reflection Survey}

We conducted a seismic reflection survey to image the subsurface structures beneath Unzen volcano in the period December 10-28, 2001. We set an approximately $15-\mathrm{km}-$ long survey line located $2 \mathrm{~km}$ to the west of the lava dome of the latest eruption. Figure 1 shows the locations of the reflection profile and active faults around Unzen volcano (The Research Group for Active Faults of Japan, 1991). The reflection profile cross-cuts the active faults and traverses the Unzen graben from north to south. The detailed reflection profile and the locations of the common midpoint (CMP) line considered in the present reflection analysis are shown in Fig. 3. Analysis has shown that reflectors are present just beneath the CMP line. The region around Unzen volcano is covered with lava and pyroclastic deposits (Hoshizumi et al., 1999, 2003), both having andesitic to dacitic composition. To the east of the profiled region are distributed (1) the lava domes of the volcanic edifices formed during the younger stage, (2) the lava domes of the latest eruption (ap- 


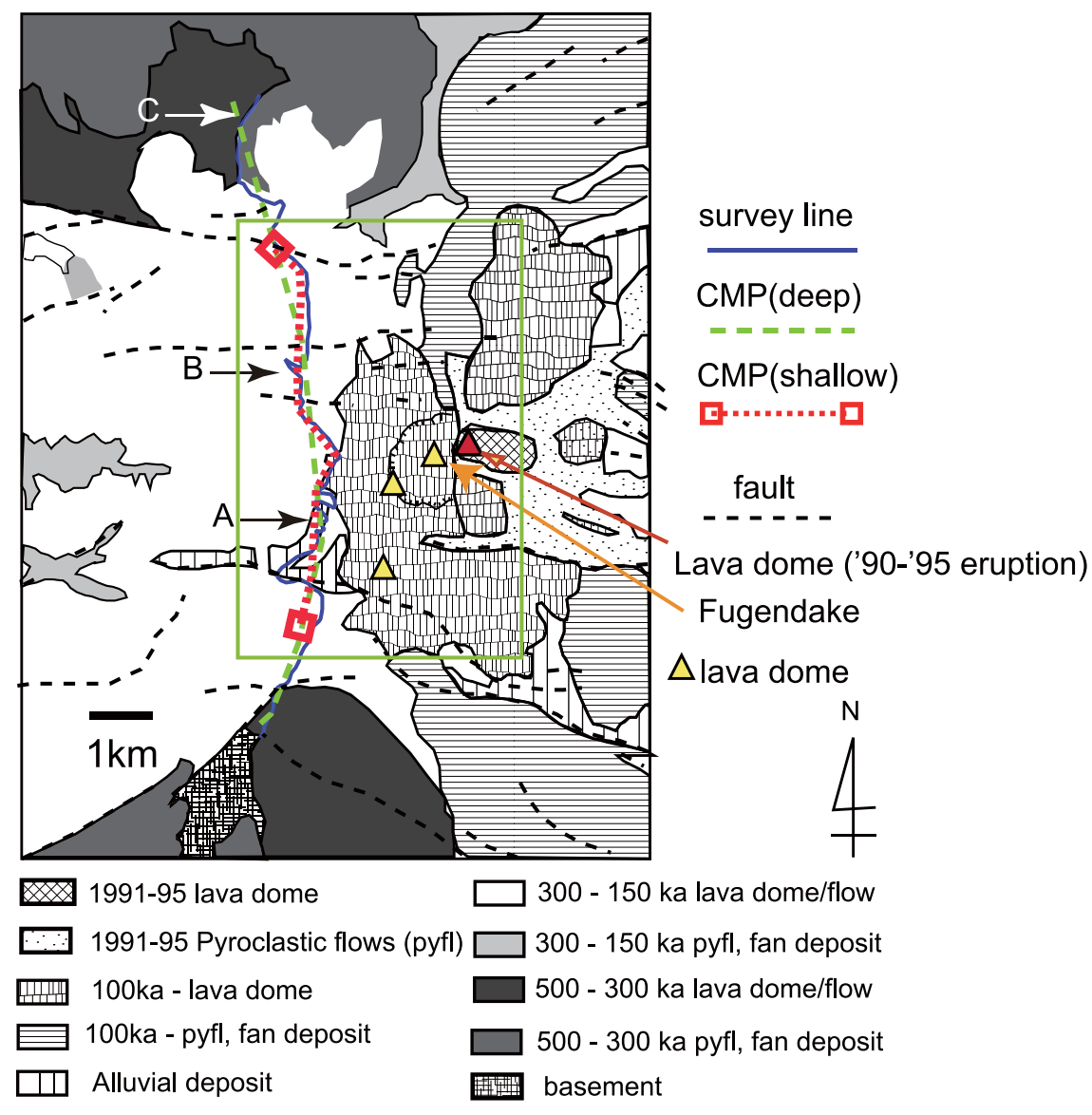

Fig. 3. Detailed configuration of the survey line and geological structure. The blue line represents the survey line along which the VPs and receivers were deployed. The green dashed and red dotted lines are the CMP lines set for processing the deep and shallow sections, respectively. The geological map and locations of lava domes reported by Hoshizumi et al. (2003) are also plotted. The hatched pattern indicates a geological feature as shown below the map. The triangles represent cones formed in the younger stage of Unzen activity. The red and yellow triangles show locations of the lava domes formed during the latest 1990-1995 eruption and during a past eruption, respectively. The black and white arrows denote the location of the vibration points for shot records in Fig. 5. The green rectangle denotes the area shown in Fig. 7.

proximately $2 \mathrm{~km}$ east of the region in the reflection profile), and (3) the flow and deposits of the latest eruption. The geological data indicate a relatively older lava flow and dome along the profile- - shown by "300-150 ka lava dome/flow" in Fig. 3-than that observed in the eastern part.

Three Vibroseis trucks (Y-2400, maximum load = $1.36 \times 10^{4} \mathrm{~kg}$, loading plate size $=1 \mathrm{~m} \times 2 \mathrm{~m}$ ) were used as seismic sources. The parameters for the survey, including the sweep parameters of the vibrators, are listed in Table 1. The vibration points (VPs) were set at an average interval of $50 \mathrm{~m}$ (range: $25-100 \mathrm{~m}$ ). The survey design, including the VP and sensor positions, is shown in Fig. 4. In the middle part of the profiled region, the VPs were deployed at $25 \mathrm{~m}$ intervals. This enabled details of the shallow structures near the lava dome of the latest eruption to be obtained. The receivers were set at intervals of $25 \mathrm{~m}$. At every shot point, 34 sweeps for the deep section, and 5 sweeps for the shallow section, were generated, as shown in Fig. 4. The total number of VPs for 34 and 5 sweeps were 201 and 80 , respectively. A large stacking number was used to accurately detect the reflected signals with a high $\mathrm{S} / \mathrm{N}$ ratio in areas with complicated structures. First, the signals at each VP were stacked and cross-correlated with the original sweep signal. Data from the sensors were then recorded
Table 1. Parameters for reflection survey.

\begin{tabular}{ll}
\hline Line & $12 \mathrm{~km}$ \\
Source & Vibrator Y-2400 \\
Sweep frequency & $8-50 \mathrm{~Hz}$ \\
Sweep length & $15 \mathrm{~s}$ \\
Sweeps per point & 34 (5 for shallow survey) \\
VP interval & $50 \mathrm{~m}$ (avr.) \\
Total points & 201 (80 for shallow survey) \\
Receiver & $10 \mathrm{~Hz}$ vertical \\
Geophone & 9 \\
Phones/site & $25 \mathrm{~m}$ \\
Interval & 589 \\
Total point & GDAPS-4 \\
Recording & $4 \mathrm{~ms}$ \\
Sampling & 580 \\
Channels & $16 \mathrm{~s} \mathrm{(after} \mathrm{correlation)}$ \\
Record length & $12.5 \mathrm{~m}$ \\
CMP interval &
\end{tabular}

by GDAPS-4 (e.g., max. channel: $1024 \times 2032$, 24-bit deltasigma AD converter, dynamic range: $120 \mathrm{~dB}$, max sampling interval: $0.5 \mathrm{~ms}$ ). Figure 5 shows examples of shot records at the three VPs $(\mathrm{A}, \mathrm{B}, \mathrm{C})$ shown in Fig. 3, obtained after 


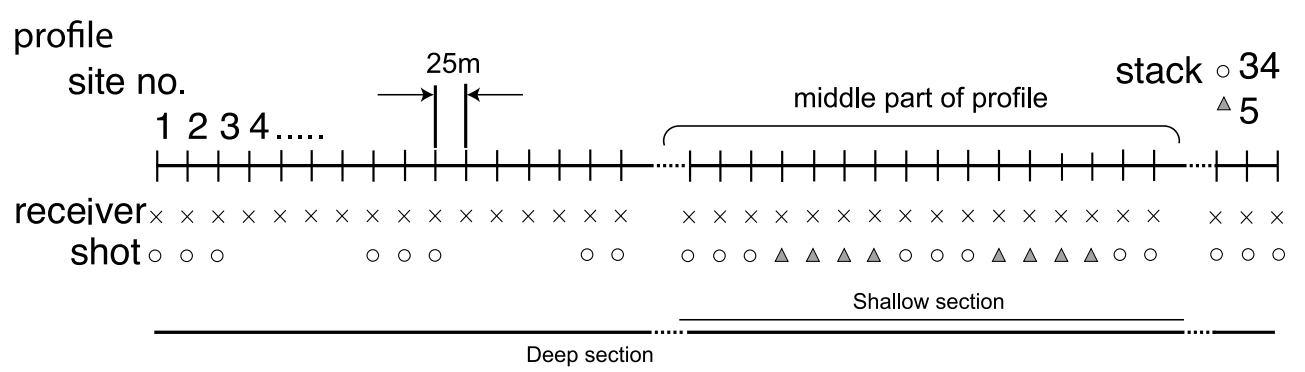

Fig. 4. The survey design of the profile used in this reflection experiment. Shot points and receiver settings are displayed. The solid bars at the bottom of the figure indicate the parts of the profile used in analyses for the deep and the shallow sections. The data processed for the shallow section are taken mainly from a part where both the vibration points and the receivers are deployed at 25-m intervals.

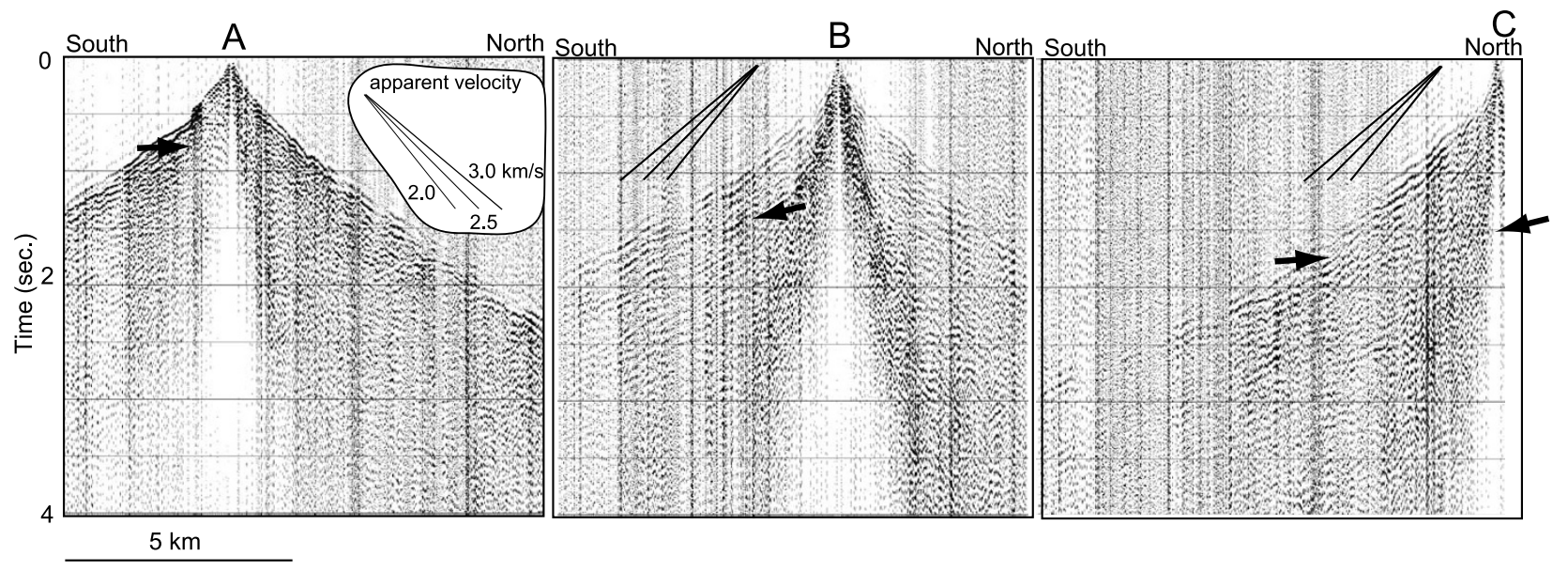

Fig. 5. Examples of waveforms induced by the shots located at the vibration points A, B, and C in Fig. 4. The apparent velocity can be obtained from the decay of travel time with distance. The solid arrows are pointing towards several reflected phases.

cross-correlation, stacking, band-pass filtering, and gain recovery (as seen in Fig. 6). The apparent velocities of the direct $P$ waves arriving at the sensors with an offset distance of a few hundred meters from the shot points are approximately $2.3-2.8 \mathrm{~km} / \mathrm{s}$, as shown in Fig. 5. In this figure, several reflected phases can be recognized at a lapse time of $2-4 \mathrm{~s}$.

\section{Data Processing}

All the data were processed using techniques employed in conventional reflection surveys. The process flowchart is shown in Fig. 6(a). Generally, in data processing in seismic exploration, the procedures adopted for imaging a subsurface structure depend on the target depth. The dataprocessing parameters must be appropriately set in order to obtain accurate imaging of the subsurface at various target

Table 2. Parameters for deep and shallow section analysis.

\begin{tabular}{lcc}
\hline \multicolumn{1}{c}{ Section } & Deep & Shallow \\
\hline Band-pass filter (Hz) & $6-40$ & $8-50$ \\
$\begin{array}{l}\text { Deconvolution filter operator } \\
\text { length (s) }\end{array}$ & 3 & 1 \\
CMP stack offset limit (m) & none & 2000 \\
$\begin{array}{l}\text { Interval of velocity analysis (m) } \\
\text { fx prediction filter operator }\end{array}$ & 625 & 312.5 \\
length (trace) & 13 & 5 \\
\hline
\end{tabular}

depths. In this study, we analyzed the reflected signals from the deep and shallow parts of the target area separately, in order to image the reflectors more accurately. The deep region has a depth of approximately $4 \mathrm{~km}$ and is shown by the green dashed line in Fig. 3. Seismic signals reflected from the relatively deeper parts of the crust are emphasized in this section (hereafter, we refer to this section as the "deep section"). The shallow part is indicated by the red dotted line in Fig. 3; for this section, the signal is analyzed only where the two-way travel time is $1 \mathrm{~s}$ or less. This traveltime limit corresponds to a maximum target depth of approximately $1 \mathrm{~km}$. The line represented by the red dotted line in Fig. 3 is called "the shallow section" in this study. The data for the shallow section was obtained from the central part of the reflection profile with VP intervals of $25 \mathrm{~m}$, as described above. We set two CMP lines for reflection processing (Fig. 3) in both sections. In this experiment, we process the data obtained from the entire deep section. On the other hand, the data for the shallow section are calculated from the center of the profiled region in order to focus only on the shallow structure beneath the central part of the profiled region. Almost identical processes were adopted for analyzing the deep and shallow sections; only the experimental parameters were changed. These experimental parameters are listed in Table 2. The experimental parameters in the shallow section were set such that a good image of the region could be obtained. Detailed description of the processing is provided in the following subsections. 
a)
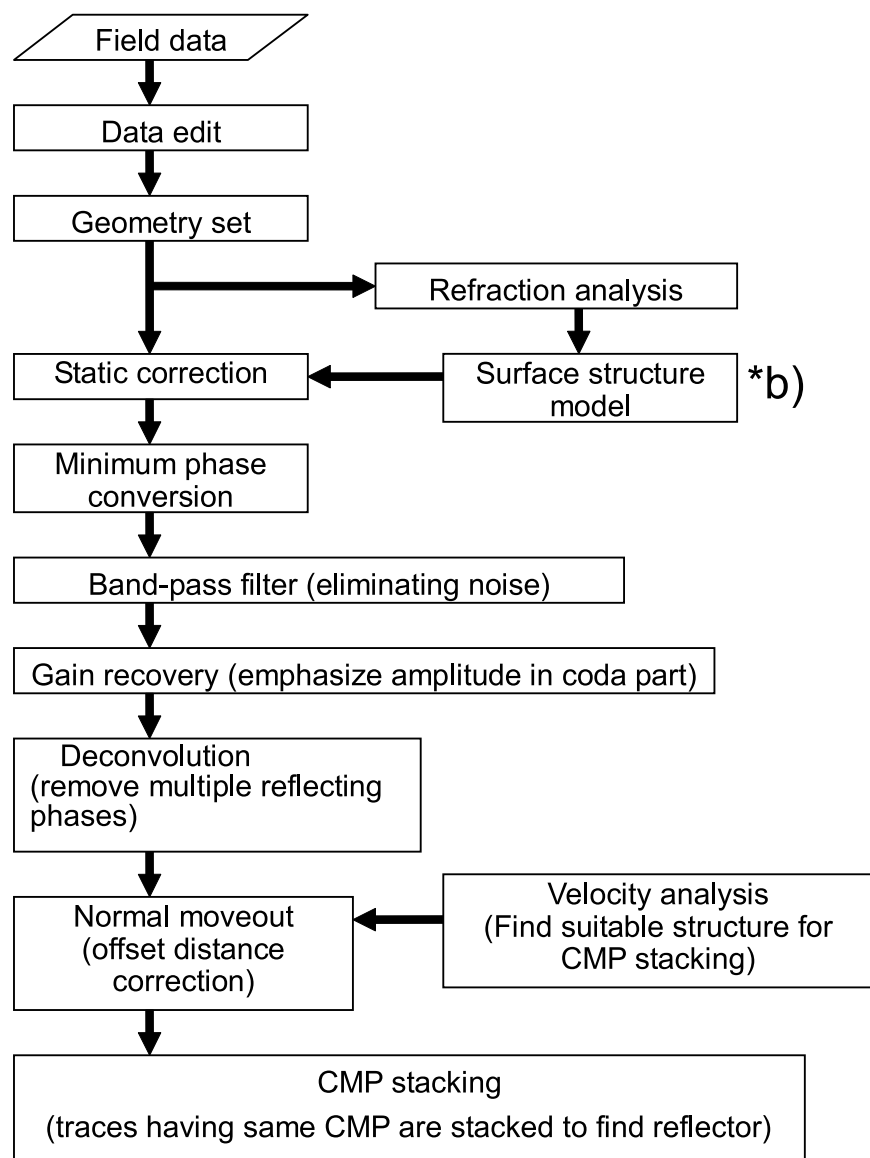

b)
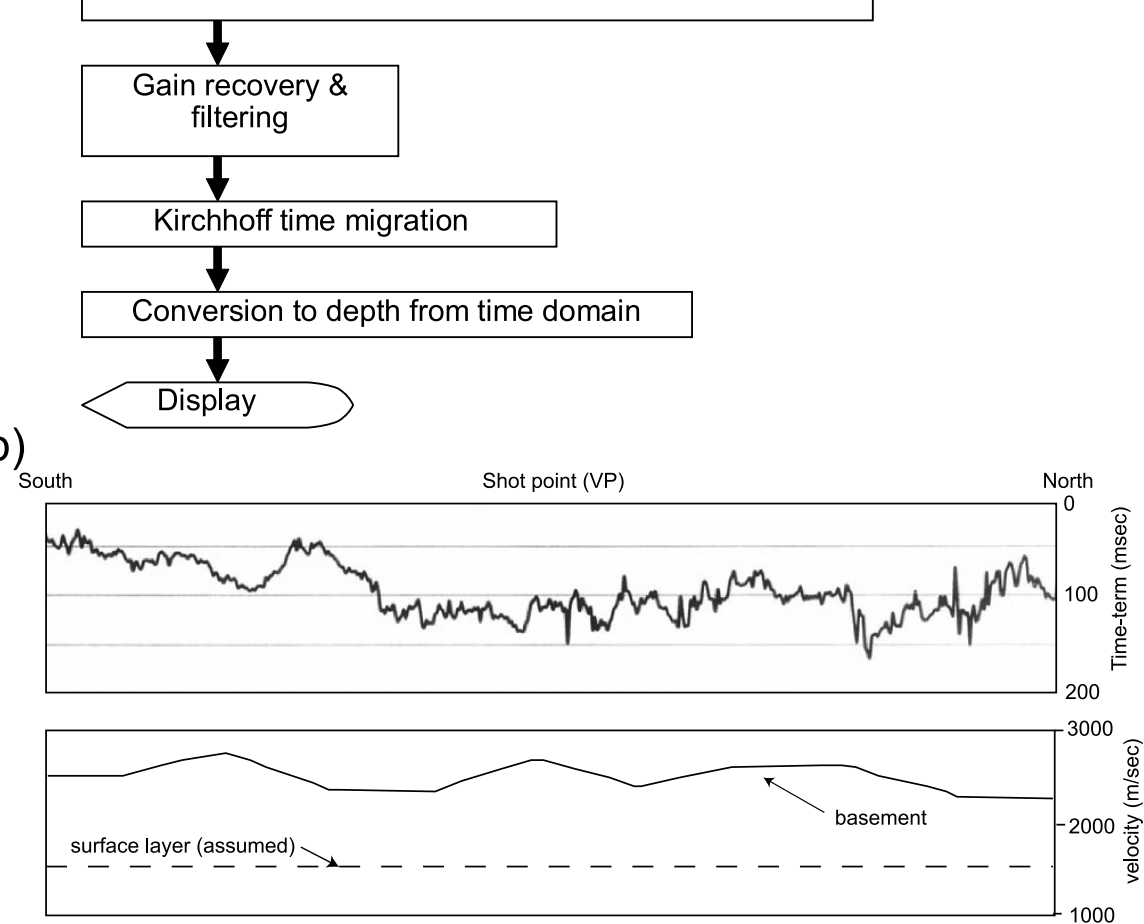

Fig. 6. (a) Flowchart of data processing and (b) time-term of the surface layer at the vibration point along the profile (upper). The lower figure shows the velocity in the second layer (basement), as obtained from the travel-time curve. The static correction factor, which eliminates the travel time through the surface layer, can be calculated from the time-term factor.

\subsection{Data processing for the deep section}

We carried out refraction analysis to eliminate the influence of velocity heterogeneities just beneath the profiled region. Time-term factors, which are commonly used in refraction exploration, for regions above a basement layer can be obtained from first-arrival time data that are picked manually from the observed seismic records. In this analysis, the basement layer is defined as a layer with a $P$ wave velocity of $2.3-2.6 \mathrm{~km} / \mathrm{s}$, as obtained from the traveltime curves. The time-term factors along the profile are 

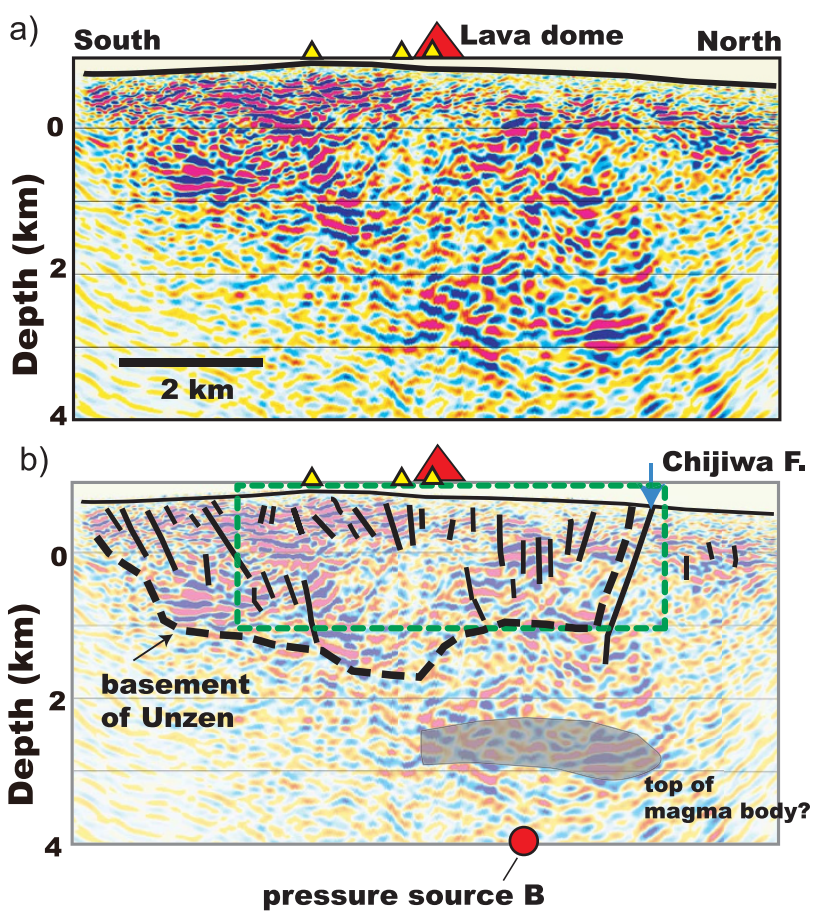

Fig. 7. (a) Depth section of the deep section and (b) interpretation of the section. The section is converted from the time section on the basis of the velocity structure obtained in the velocity analysis. The solid lines in (b) indicate faults in the section. The hatched area covering the reflectors, at and around, a depth of $3 \mathrm{~km}$ is interpreted as the top of the magma body. The red circle denotes the location of the pressure source during eruption, as obtained by Kohno et al. (2008). The dashed green square shows the shallow section (shown in Fig. 8).

shown in Fig. 6(b). The static correction factors were determined from estimated time-term, sub-weathering velocity and assumed weathering velocity $(1.5 \mathrm{~km} / \mathrm{s})$. This is a static correction commonly used to improve stacking images between traces in reflection analysis. The survey line is deployed at the surface of a mountainous region. Therefore, we defined a floating datum for static correction. The final section was obtained below the floating datum. Velocity analysis with a velocity sampling interval of $62.5 \mathrm{~m}$ (i.e., 50 CMPs) was performed after static correction, band-pass filtering, gain recovery, and spiking deconvolution. Generally, the velocity increases from north to south. On the basis of the velocity structure obtained in the velocity analysis, a normal moveout (NMO) correction was applied to the traces. The section of reflected phases beneath the CMP line was derived after CMP stacking and Kirchhoff migration in the time domain. The maximum number of folds for CMP stacking was 384 at the center of the profile. Finally, the stacked section in the time domain was transformed to depth using the velocity structure interpolated from the structure obtained in the velocity analysis. The deep section is shown in Fig. 7.

\subsection{Data processing for the shallow section}

In the static correction for the shallow section, the velocity in the sub-weathered layer was assumed to be 1.5$1.97 \mathrm{~km} / \mathrm{s}$, as obtained from the travel-time curves. The layer with the lower velocity is assumed to be the basement layer in the static correction, which provides an image of shallow layers, because a shallow layer usually has a

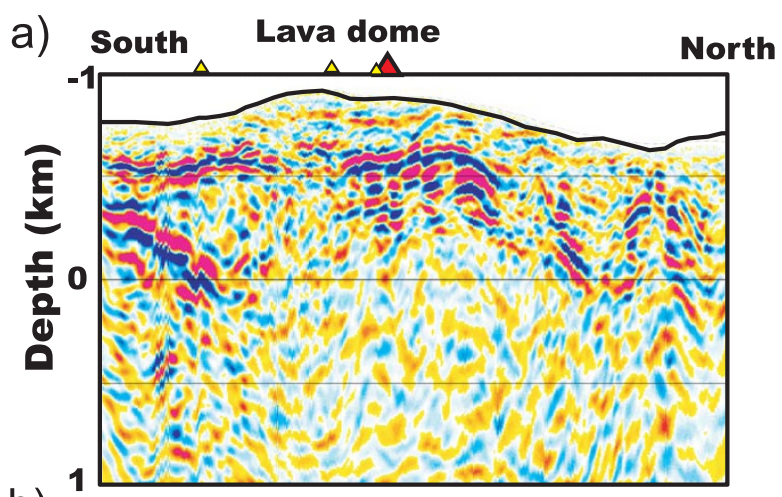

b)

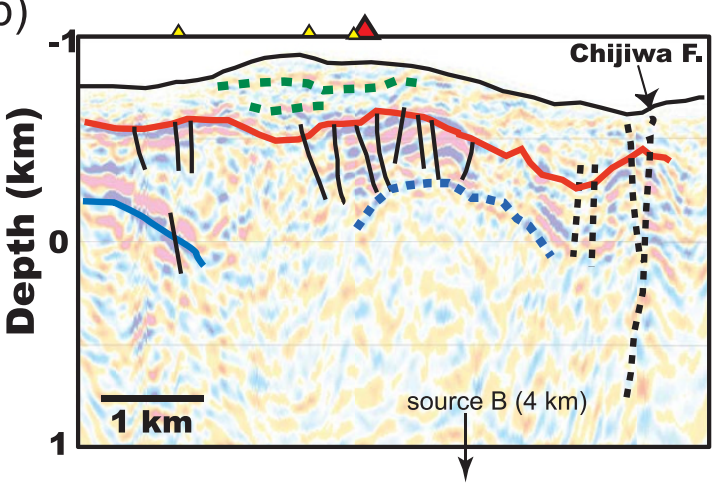

Fig. 8. Reflection cross-section for the shallow section: (a) section in the depth domain and (b) its interpretation. The section is converted from the time domain on the basis of the velocity structure obtained in this shallow analysis. The black lines denote the faults in the section. The blue line indicates a reflector showing the undulation structure. The dashed line can be interpreted as the head of the magma body.

lower velocity property than that in the layers below them. Therefore, a detailed velocity analysis is needed in order to resolve complicated surface structure. Velocity analysis was performed for the traces at CMP locations chosen every $31.25 \mathrm{~m}$ along the CMP line, (i.e. half that for the deepsection analysis). After velocity analysis, NMO correction and CMP stacking were carried out. As mentioned above, a maximum offset distance of $2 \mathrm{~km}$ was adopted for CMP stacking, which provided fine images in the shallow part. Then, the image of the shallow section in the time domain was obtained and Kirchhoff migration in the time domain was carried out. Depth conversion of the section from the time domain was performed on the basis of the results of velocity analysis. The reflection cross-section of the shallow section is shown in Fig. 8.

\section{Interpretation of Seismic Section}

We imaged many strong reflectors with a heterogeneous distribution in the deep section (Fig. 7(a)), and observed several distinctive features. The prominent reflectors are found above sea level and have a deflecting shape and horizontal segmentation structure, as shown in Fig. 7(b), suggesting the existence of many faults in this region. The dip angles of many of the faults beneath the profile are greater than $60^{\circ}$. These faults are recognized either in sections in which the reflector disappears, or in sections in which there are gaps in the longitudinal direction of the reflector. Most of the faults are classified as normal faults on the basis of the relationship between the direction of dip of the fault and 
the direction of subsidence of the re ector. The existence of these normal faults suggests that this area was transformed into a graben under a tensile stress eld, as suggested by previous geological studies (e.g., Hoshizumi et al., 2005). Some of the fault traces coincide with active faults at the surface (see Figs. 1 and 3). The largest active fault in this area, called the Chijiwa fault, is observed in a seismic section as a re ector gap over a wide depth range (i.e., from 1 to $1.5 \mathrm{~km}$ at least). In this study, active faults as well as many subsurface faults are observed at the surface.

The lower depth limit of the re ective layer, shown in Fig. 7(b) as a dashed line, becomes shallower with increasing distance from the center of the pro le. The depth of the lower limit varies from about $1.5 \mathrm{~km}$ below sea level to about $0.3 \mathrm{~km}$ above sea level. This feature is consistent with a typical graben structure and supports the geological model that Unzen volcano is located at the center of the Unzen graben. The shape traced by the dashed line in Fig. 7(b) is similar to the shape of the basement of the Unzen graben as derived in the geological studies of Hoshizumi et al. (1999, 2005). They estimated the basement structure from a geological survey, and well-log data, and suggested that the basement formed by Unzen volcanic activity after $0.5 \mathrm{Ma}$ is about $1.0-\mathrm{km}$ deep in the eastern and western parts of Shimabara Peninsula. Below the depth indicated by the dashed line in Fig. 7(b), the re ectors disappear, indicating that the layer formed before $0.5 \mathrm{Ma}$ is relatively homogeneous. The depth of the basement, as determined in the present study, is a few hundred meters greater than the depth of the basement as determined in the geological study. This could be due to the uncertainty in the determination of the basement depth in the geological study. Another possible reason is that, in the geological study, the well-log geological cross-section was determined for the eastern and western parts of Shimabara peninsula (i.e., away from the pro led region) and not around the region pro led in the present study.

Strong re ectors can be observed at a depth of about $3 \mathrm{~km}$ towards the north of the lava dome. These re ectors were spread over approximately $4 \mathrm{~km}$ in a direction parallel to the pro le (i.e., N-S). The arrival of many strongly re ected phases suggests that the structure at a depth of $3 \mathrm{~km}$ is complex and is composed of layers with strong impedance contrasts. Kohno et al. (2008) estimated the locations of the pressure sources activated by the latest eruption from geodetic data using a point source assumption. According to their results, the source $B$ is located just beneath these reectors (Fig. 7(b)). Source B is not located directly beneath the lava dome; rather, it is located to the north of the dome just beneath the pro led region.

In the shallow section, some detailed structures are observed directly beneath the center of the pro le. The shallow section, and its interpretation, are shown in Fig. 8. Reectors that are subparallel to the surface can be found in the shallowest part of the section. Beneath these re ectors, a vertical undulation of re ectors between depths of about $-0.5 \mathrm{~km}$ and $-0.2 \mathrm{~km}$ is noticeable (e.g., re ectors between the red line and the dashed blue line in Fig. 8(b)). The location of this undulation in the N-S cross-section is just above the pressure source $B$, estimated from the geode- tic study, and is beneath the latest lava dome. Many faults with a high dip angle are seen in these undulated re ectors. The type of these faults is considered to be a normal fault due to the extension force contributing to the growth of the Unzen graben. Similarly, the fact that the faults have high dip angles suggests that the normal faulting may have occurred due to a kind of intrusion accompanied by anticline formation of the strati ed layer.

\section{Discussion}

Unzen volcano has developed within a graben structure due to an N-S oriented extensional stress eld (Hoshizumi et al., 2003). The growth of the graben could have been accompanied by syncline formation and normal faulting. Many normal faults with high dip angles, which are characteristic of a graben structure, are predominant in the target region, as shown in Fig. 8. Generally, the re ective area at depths shallower than $1 \mathrm{~km}$ corresponds to the graben structure in the younger stage $(<120 \mathrm{ka})$ as described in the previous section by the geological study. Many re ectors, however, are deformed just beneath the cones formed in the younger stage. In the shallow section, where the depth ranges from approximately $-0.5 \mathrm{~km}$ to $-0.2 \mathrm{~km}$, the re ectors are undulated and anticlinal beneath the lava domes. The lava domes in the younger stage are distributed in the region between the pro le and the most recent lava dome, as shown in Fig. 3. It is reasonable to consider that the conduit contributing to Unzen volcano formation developed in the region around the pro le; thus, conduits in both the latest eruption and the younger stage exit there. If magma intrudes into a syncline structure due to graben formation, the basement of the structure would be deformed and a local anticline would develop just above the position of magma intrusion. This feature can be observed in the shallow section in Fig. 8(a); here, the basement structure seems to be deformed due to magma intrusion. However, this intrusion did not occur during the latest eruption, since geodetic analysis did not reveal any large subsurface uplift. Without considering the growth of the lava dome, the maximum vertical deformation of the latest eruption was less than $10 \mathrm{~cm}$, although the height of the local anticline shown in Fig. 8(b) appears to be $0.1 \mathrm{~km}$ at most. Therefore, this deformation of the layer could have occurred in the past. Moreover, this deformation might have occurred during past eruptions; this is supported by the presence of multiple dykes and veins in the vicinity of this region, as determined by USDP-4 (Nakada et al., 2005). The undulation of the re ectors can be observed in the $3 \mathrm{D}$ velocity structure of this area, as described by Nishi (2002). He obtained the velocity structure from refraction experiments involving arti cial explosions in and around our target area. The locations of the re ectors are plotted in Fig. 9 on the velocity structure reported by Nishi (2002).

Four pressure sources under Unzen volcano were detected by Kohno et al. (2008). The sources A and B are within our target depth range, as shown in Fig. 2. The source A, located beneath the latest lava dome, could not be found in the seismic sections in the present study since it is located approximately $2 \mathrm{~km}$ east of the pro le and could not be detected by seismic waves. In other words, the radius of 


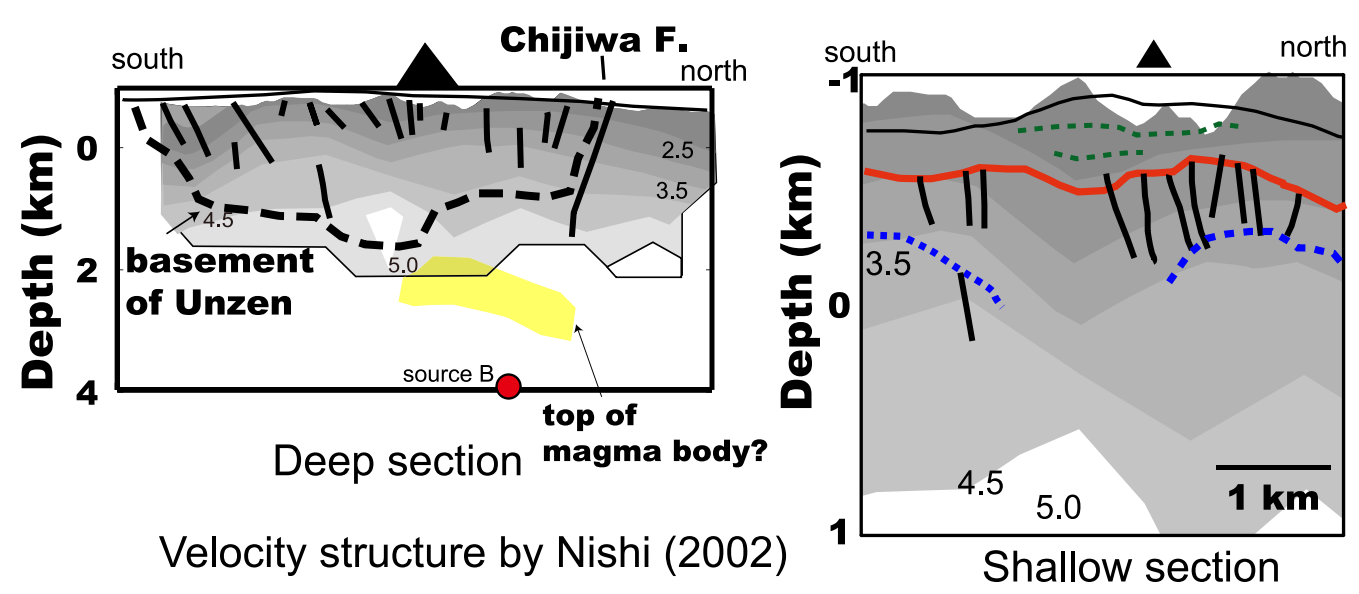

Fig. 9. The velocity structure estimated by Nishi (2002) is shown for comparison. The faults and reflectors, as shown in both Figs. 7 and 8 , are plotted together. The numbers shown in the figure indicate the velocity in $\mathrm{km} / \mathrm{s}$ obtained from the study of Nishi (2002).

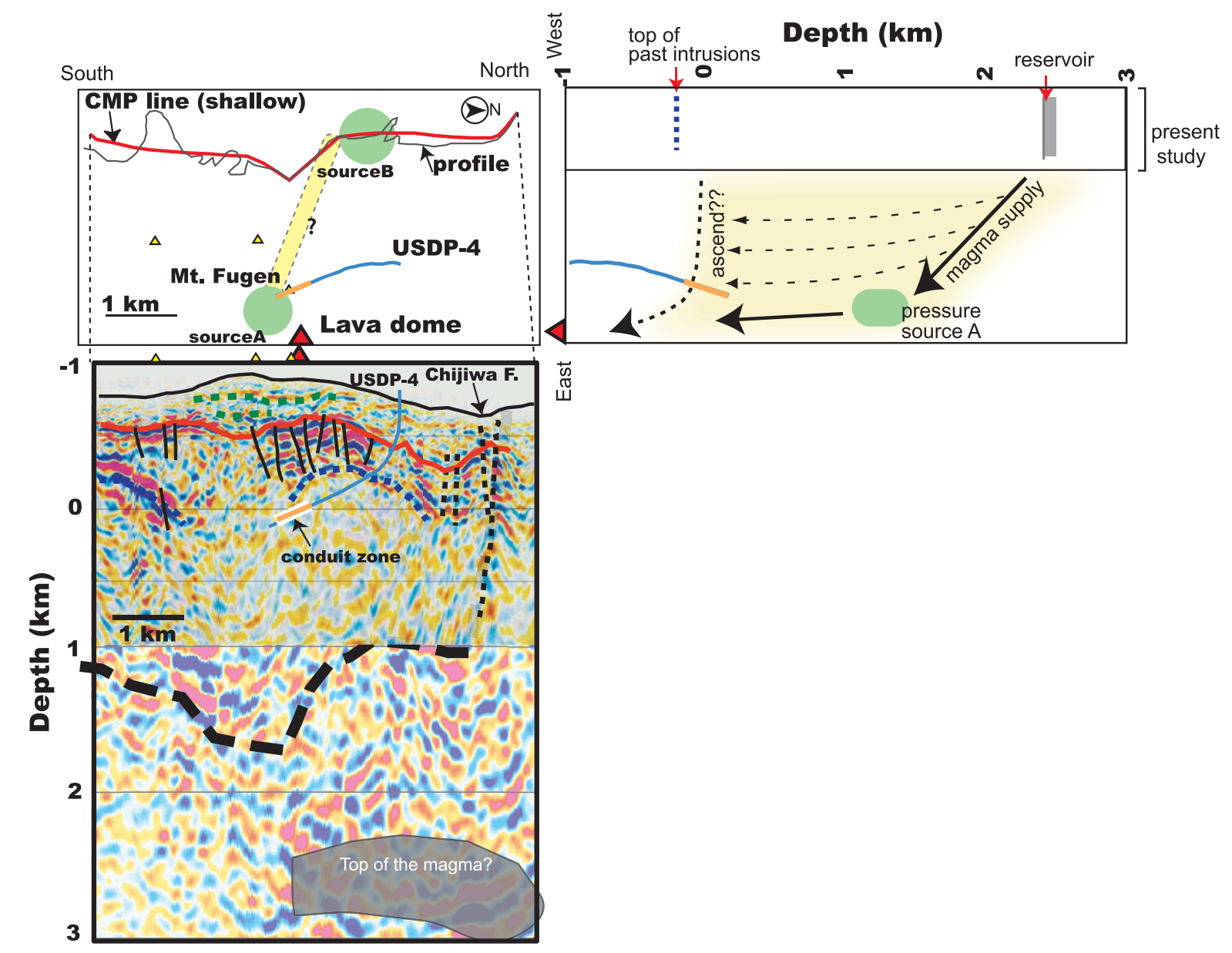

Fig. 10. Trace of USDP-4 drilling with the merged sections of Figs. 7 and 8. The upper left figure shows the trace map view of the USDP-4 borehole, the profile, and the CMP line of the reflection survey. The red and yellow triangles show the lava dome formed in the latest and older eruptions, respectively. The green circle shows the location of the pressure sources estimated by Kohno et al. (2008). The size of the green circles is arbitrary. The lower figure indicates the trace and the shallow section. The interpreted reflector and fault are also plotted. The blue line denotes the trace of USDP-4. The orange part of the trace indicates the conduit zone defined by Nakada et al. (2005). The upper right figure shows the interpretation and the E-W cross-section of the model. The solid rectangle denotes the resolved area in this study. The yellow area is the conduit zone inferred from our results and previous studies. The dashed arrows indicate the path of magma supply from source B to A.

A must be smaller than at least $2 \mathrm{~km}$. The reflector located at a depth of about $3 \mathrm{~km}$ corresponds to the horizontal location of the source B. The depth of this source was estimated to be $4 \mathrm{~km}$ and, therefore, there is a difference of $1 \mathrm{~km}$ be- tween the depths of the source and the reflector. In their analysis, the pressure sources were assumed to be small spherical regions. The locations of the pressure sources can be considered to be the centers of the pressure sources and 
do not depend on material properties as long as the medium under consideration is a Poisson solid. Thus, we can assume that the location of $\mathrm{B}$ coincides with the center of the pressure source. Because the size of the source could not be estimated, we could not directly compare the results of Kohno et al. (2008) with our re ector distribution. However, it is straightforward to consider that the re ectors correspond to the magma chamber, since the estimated pressure sources activated in the latest eruption contrast strongly, in terms of velocity and/or density, with the background rocks. Therefore, the re ectors could image either the top of the magma chamber, which possibly contributed to the latest eruption, or the water distribution in a hydrothermal system related to the magma chamber. Assuming that the upper edge and center of the magma chamber are located around the re ector and the pressure source, the size of the chamber (i.e., pressure source B) in the vertical direction can be estimated to be approximately $1 \mathrm{~km}$. The width of the chamber is estimated to be approximately $3 \mathrm{~km}$ on the basis of the horizontal extension of the re ector. This chamber is comparable in width to that of the Campi Flegrei volcano, as determined by Zollo et al. (2008). They analyzed the re ection records obtained at the Campi Flegrei caldera in detail and, through amplitude versus offset analysis, they showed that the melt zone spread laterally over several kilometres. In the case of Mount St. Helens, where effusion of dacitic lava similar to the case of Unzen volcano was reported, the size of the magma reservoir was approximately $2-3 \mathrm{~km}$, as inferred from the $P$-velocity structure (Lees, 1992). Magma chambers with similar dimensions were found in Izu and Kilauea (Owen et al., 2000; Toda et al., 2002). Therefore, we can conclude that the magma chamber at Unzen volcano is not extremely large, but standard in size.

We consider a probable model of the magma supply system at Unzen volcano on the basis of the results obtained in this study, and in recent studies conducted by other researchers. A six-year drilling project, USDP, was conducted in the target region, starting April 1999. The trace of the USDP-4 drill hole and the merged deep and shallow sections are shown in Fig. 10. In this gure, the USDP-4 trace, shown in orange, corresponds to the conduit zone reported by Nakada et al. (2005). The conduit zone contains multiple dykes of different ages, including materials deposited during the latest 1990-1995 eruption. The conduit zone is located away from the undulation structure in the re ection section towards the south. The horizontal distance (i.e., in the E-W direction) from the borehole to the pro le is approximately $1 \mathrm{~km}$. Therefore, we cannot conclude that the conduit discovered by the USDP-4 is identical to that in our survey because of the difference in the horizontal locations. However, there is a possibility that the conduit found in the drilling project connects to the magma chamber because a method of transporting magma from the reservoir beneath the pro le to the lava dome is required.

There is abundant information about the past eruptions of Unzen Volcano. Some of the information can be summarized as follows: (1) Mt. Fugen was formed in eruptions that occurred after $0.5 \mathrm{Ma}$. (2) Multiple conduits and veins were found near Mt. Fugen during USDP-4. (3) The anticline structure observed was not formed during the latest erup- tion. (4) The pressure sources B and A were activated during the last eruption. Accordingly, a conduit from B to Mt. Fugen should have existed to feed magma during the last eruption. If the source B existed during the past eruptions and formed the anticline structure, the conduit must also have existed since these past eruptions. We can then consider that the magma spread and ascended from the reservoir B beneath the pro le to A. This implies that the path of magma in the last eruption was similar to that in previous eruptions. On the basis of the above features (i.e., (1) to (4)), we can create a qualitative model of the magma supply system at Unzen volcano. This model is schematically shown in Fig. 10.

(a) Magma intrusion into Unzen graben occurred concomitantly with the growth of the graben. This intrusion led to the formation of an anticline structure.

(b) The magma ascended and spread horizontally as a dyke intrusion (yellow part in Fig. 10). Some part of the magma reached Mt. Fugen and erupted.

(c) During the latest 1990-1995 eruption, the magma supplied from pressure source B to the lava dome via pressure source A followed a similar path to that of past eruptions. This model suggests that the conduit should connect $\mathrm{B}$ to $\mathrm{A}$. In this case, the shortest path to $\mathrm{A}$ from $B$ is in the eastwards direction.

The magma chamber and the layered structure beneath the Mid-Atlantic Ridge were found by Singh et al. (2006). The structure is similar to that obtained in the present study. The re ection from the top of the magma chamber occurs approximately $3 \mathrm{~km}$ beneath the sea oor; the layered structure also has the characteristics of a graben. Singh et al. (2006) observed the axial valley bounding faults that appeared to penetrate down to the depth of the magma chamber. The characteristics of the faults is similar to those observed in our result. Therefore, the graben structure obtained in this study can be considered typical for a volcano growing in an extensional eld, even though the compositions of the rocks at Unzen volcano and at mid-ocean ridges are different (namely dacitic in the case of the former and basaltic in the case of the latter).

\section{Conclusions}

We carried out a seismic re ection survey in the Unzen graben using vibrators, and obtained several interesting results from the processed depth sections. These results are summarized as follows:

(1) The Unzen graben is dominated by normal faults with dips greater than $60^{\circ}$, suggesting the existence of a subsurface graben structure.

(2) Strong re ectors occur at depths of approximately $3 \mathrm{~km}$. This could be related to the material from the magma body based on the geometrical correspondence between locations of the re ectors and of the magma body deduced from geodetic study.

(3) The re ecting zone continues up to sea level. The base of the zone appears to correspond to the basement of Unzen volcano inferred from geological studies. 
Thus, it is dif cult to completely understand the mechanism of the eruptions in Unzen volcano. We can describe a possible case with regard to the magma supply system in the present, and the past, eruptions based on the results presented above.

(a) The undulation structure was formed by an activity related to source $B$.

(b) The small change in the volume of source $\mathrm{B}$ in the latest eruption could not deform the subsurface layer. Therefore, the magma intrusion that led to the formation of source B did not occur during the latest eruption but during a past event.

(c) Source B might be approximately $3 \mathrm{~km}$ in length and $1 \mathrm{~km}$ from the center of the source to the top according to the shape of the re ector and the relation between the source and the re ector.

(d) Magma supply during the latest eruption from source B to source A, as suggested in previous geodetic studies, could not be found in any image of the conduit from source A to B.

Acknowledgments. We wish to thank all the staff and students of the Institute of Seismology and Volcanology, Kyushu University, who helped in carrying out this survey. We are grateful to the anonymous reviewers for their insightful and critical discussion of this paper. We also thank Drs. Uraki and Higashinaka of the Japex Geoscience Institute for their efforts in carrying out the reection analysis. We are grateful to Dr. Umakoshi for his valuable comments and discussions and for giving us access to hypocenter data. This study was supported by Unzen Scienti c Drilling Project, funded by the Ministry of Education, Culture, Sports, Science and Technology, Japan.

\section{References}

Collier, J. S. and M. C. Sinha, Seismic images of a magma chamber beneath the Lau Basin back-arc spreading centre, Nature, 346, 646-648, 1990.

Hoshizumi, H., K. Uto, and K. Watanabe, Geology and Eruptive History of Unzen Volcano, Shimabara Peninsula, Kyushu, SW Japan, J. Volcanol. Geotherm. Res., 89, 81-94, 1999.

Hoshizumi, H., K. Uto, and A. Matsumoto, Geology and Petrology of Unzen Volcano. Field Guidebook, A3: Unzen and Aso Volcanoes, pp. 11
XXIII General Assembly of the International Union of Geodesy and Geophysics, 2003.

Hoshizumi, H., K. Uto, A. Matsumoto, and A. Kurihara, Growth history of Unzen volcano, Kyushu, Japan-Results of two ank drillings of the Unzen Scienti c Drilling Project, Unzen Workshop 2005: Extended Abstract Volume, 37-38, 2005.

Kohno, Y., T. Matsushima, and H. Shimizu, Pressure sources beneath Unzen Volcano inferred from leveling and GPS data, J. Volcanol. Geotherm. Res., doi:10.1016/j.jvolgeores.2008.03.022, 2008.

Lees, J. M., The magma system of Mount St. Helens: non-linear highresolution P-wave tomography, J. Volcanol. Geotherm. Res., 53, 103$116,1992$.

Nakada, S., H. Shimizu, and K. Ohta, Overview of the 1990-1995 eruption at Unzen Volcano, J. Volcanol. Geotherm. Res., 89, 1-22, 1999.

Nakada, S., K. Uto, S. Sakuma, J. C. Eichelberger, and H. Shimizu, Scienti c results of conduit drilling in the Unzen Scienti c Drilling Project (USDP), Sci. Drill., 1, 18-22, 2005.

Nishi, K., Three-dimensional seismic velocity structure beneath Unzen Volcano, Kyushu, Japan inferred by tomography from experimental explosion data, Bull. Volcanol. Soc. Jpn., 47, 227-241, 2002.

Owen, S., P. Segall, M. Lisowski, M. Murray, M. Bevis, and J. Foster, January 30, 1997 eruptive event on Kilauea Volcano, Hawaii, as monitored by continuous GPS, Geophys. Res. Lett., 27, 2757-2760, 2000.

Singh, S. C., W. C. Crawford, H. Carton, T. Seher, V. Combier, M. Cannat, J. P. Canales, D. Dusunur, J. Escartin, and J. M. Miranda, Discovery of a magma chamber and faults beneath a Mid-Atlantic Ridge hydrothermal eld, Nature, 422, 1029-1032, doi:10.1038/nature05105, 2006.

Suzuki, H., K. Kasahara, M. Ohtake, A. Takahashi, T. Ikawa, S. Abe, and Y. Kawabe, Underground structure and magmatic activity of IzuOshima volcano, Japan as inferred from seismic re ection survey, $J$. Volcanol. Geotherm. Res., 49, 105-117, 1992.

The Research Group for Active Faults of Japan, Active Faults in Japan: Sheet Maps and Inventories (revised edition), pp. 358-363, University of Tokyo Press, Tokyo, 1991.

Toda, S., S. Ross, and T. Sagiya, Evidence from the AD 2000 Izu islands earthquake swarm that stressing rate governs seismicity, Nature, 419, 58-61, 2002.

Umakoshi, K., H. Shimizu, and N. Matsuwo, Volcano-tectonic seismicity at Unzen Volcano, Japan, 1985-1999, J. Volcanol. Geotherm. Res., 112, 117-131, 2001.

Zollo, A., N. Maercklin, M. Vassallo, D. D. Iacono, J. Virieux, and P. Gasparini, Seismic re ections reveal a massive melt layer feeding Campi Flegrei caldera, Geophys. Res. Lett., 35, L12306, doi:10.1029/2008GL034242, 2008.

S. Matsumoto (e-mail: matumoto@sevo.kyushu-u.ac.jp), H. Shimizu, M. Onishi, and K. Uehira 